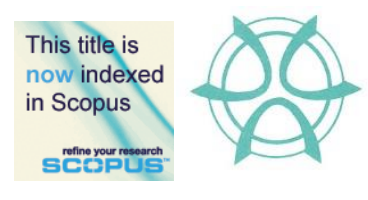

PLANNING MALAYSIA:

Journal of the Malaysian Institute of Planners

VOLUME 16 ISSUE 1 (2018), Page 155 - 162

\title{
COMMUNITY AWARENESS ON THE IMPLEMENTATION OF EARLY WARNING SYSTEM AT TENAGA NASIONAL BERHAD SULTAN ABU BAKAR HYDROELECTRIC SCHEME, LEMBAH BERTAM, CAMERON HIGHLAND
}

\author{
Mohd Ramzi Mohd Hussain ${ }^{1}$, Ismawi Zen², Rahsidi Sabri Muda ${ }^{3}$, Sivadass \\ Thiruchelvam ${ }^{4}$, Izawati Tukiman ${ }^{5}, \&$ Aishah Naqiah Ahmad Shazili ${ }^{6}$ \\ ${ }^{1,5,6}$ Kulliyyah of Architecture and Environmental Design \\ INTERNATIONAL ISLAMIC UNIVERSITY MALAYSIA \\ ${ }^{2}$ AL-MADINAH INTERNATIONAL UNIVERSITY \\ ${ }^{3}$ TNB RESEARCH SDN. BHD. \\ ${ }^{4}$ Department of Civil Engineering \\ UNIVERSITI TENAGA NASIONAL
}

\begin{abstract}
This article presents the community awareness on the implementation of Early Warning System (EWS) in a well-planned Integrated Community-Based Disaster Management (ICBDM) that covers all Tenaga Nasional Berhad's (TNB) hydroelectric schemes. In Cameron Highland, Lembah Bertam and further downstream villages were reported to have the highest occurrence of floods especially during monsoon season, which makes the area vulnerable. This study incorporates and synergizes three major stakeholders; the community; local authority; and TNB; gearing towards minimizing loss of life and property damages in the event of a dam related disaster. The aim of this article is to assess the level of awareness and perceptions of the directly affected communities towards the implementation of EWS. Their heightened awareness would help to reduce their vulnerability in the event of future disaster. This study opted for a quantitative approach, which included a questionnaire survey. The findings revealed that the demographic characteristics influenced community awareness regarding the implementation of EWS. Most of the respondents accepted the EWS positively and understood the importance of EWS. Thus, the community members have the right to know and understand the hazard they should be expecting so they can plan for themselves and make informed choices to reduce their vulnerability.
\end{abstract}

Keyword: community awareness, Early Warning System (EWS), disaster, vulnerability 
Mohd Ramzi, Ismawi Zen, Rahsidi Sabri, Sivadass Thiruchelvam, Izawati Tukiman, \& Aishah Naqiah

Community Awareness on the Implementation of Early Warning System at Tenaga Nasional Berhad Sultan Abu Bakar

Hydroelectric Scheme, Lembah Bertam, Cameron Highland

\section{INTRODUCTION}

Despite their many beneficial uses and value, dams also present risks to properties and lives of their surrounding communities. This is due to their potential to fail and cause catastrophic flooding. Dam break or failure is considered as one of the events of "small probability, large consequences", which has often lead to catastrophic loss of lives, as well as destructions of the social, economic and environmental components of downstream areas.

In Lembah Bertam, Cameron Highlands, indiscriminate land clearing for agricultural development in the upstream of Sultan Abu Bakar Hydroelectric dam has resulted in multiple flood events in the downstream areas of the dam. Considering that community's awareness can significantly reduce the vulnerability of the group, this research focuses on understanding the community's awareness on the implementation of EWS in order to reduce their vulnerability in the event of a disaster.

Early Warning System (EWS) is the representation of a set of capacities needed to generate and disseminate timely and meaningful warning information that enables at-risk individuals, communities and organizations to prepare and act accordingly, and in sufficient time to reduce harm or loss (UNISDR 2009). EWS can be categorised into community managed EWS and community based EWS. A community managed EWS refers to the system managed by community but they are not completely involved in the establishment of the system. Whereas, community based EWS is a system developed, operated and maintained by the community itself. While developing the system, the community would explore external support from different individuals, communities, organizations and institutions. It is necessary that the community develops and maintains close coordination and links with the stakeholders.

As EWS tends to focus on warning and monitoring on hazards and threats only, the vulnerability factor of the community is often neglected. Hazards and vulnerability should be assessed together to reduce risks. A community which is highly exposed to hazard also experiences a high level of vulnerability and needs a more heads-up warning. Thus, the objectives of this article is to assess community awareness and perceptions towards EWS implementation to mitigate risks due to any failure and probable failure of the TNB Sultan Abu Bakar HydroElectric Dam. 


\section{DISASTER MANAGEMENT CYCLE}

Disaster management cycle provides the framework for disaster management. In Nepal, its disaster management cycle consists of two phases - before and after the disaster, and under this cycle is where the implementation of EWS takes place (Figure 1). EWS is part of Risk Management, which is before disaster occurs, and consists of preparedness, mitigation and prevention action. Whereas, the action of response, rehabilitation and reconstruction falls under the category Crisis Management, which is after the occurrence of a disaster.

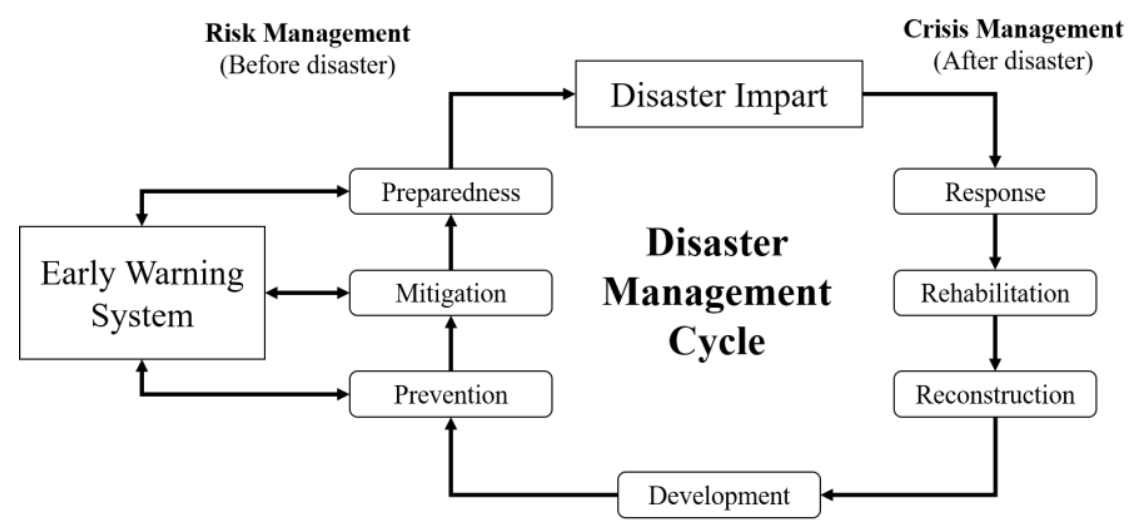

Figure 1: Nepal's disaster management cycle. Source: Mercy Corps Nepal (2010).

Likewise, the disaster management cycle for Malaysia is also divided into two phases - risk management that focuses on protection and crisis management that focuses on recovery (Figure 2). The components under Risk Management (protection) are mitigation, preparedness, prediction and EWS. Meanwhile, the components under Crisis Management (recovery) are impact assessment, response, recovery and reconstruction.

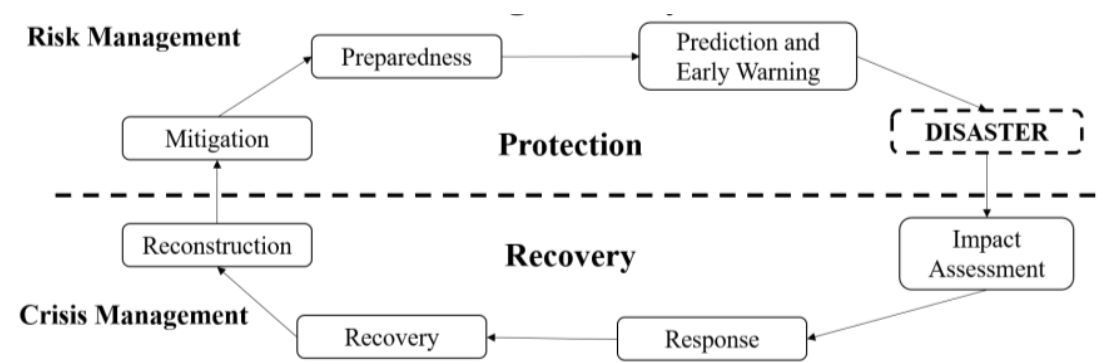

Figure 2: Malaysia's disaster management cycle.

Source: slideshow Disaster Management in Malaysia: Landscape Review, Challenges and Prospects 
Mohd Ramzi, Ismawi Zen, Rahsidi Sabri, Sivadass Thiruchelvam, Izawati Tukiman, \& Aishah Naqiah

Community Awareness on the Implementation of Early Warning System at Tenaga Nasional Berhad Sultan Abu Bakar

Hydroelectric Scheme, Lembah Bertam, Cameron Highland

Based on the disaster management cycles of the two countries, it can be seen that both cycles consist of similar components but with a slight difference in their emphasis towards EWS. Nepal's disaster management cycle is more focus and more detailed in EWS compared to Malaysia's. In Nepal's, EWS is a main system that is being employed to integrate the other components under risk management. Whereas, in Malaysia, EWS is only one of the Risk Management components. The differences in the emphasis and utilization of EWS are what differentiate between the two countries' disaster management cycles and determine the success of the cycles.

\section{COMMUNITY PERCEPTION AND DISASTER AWARENESS}

The community, which is exposed to potential threat of disaster, is the most vulnerable between all the stakeholders. Vulnerable community needs to be aware of the potential threats and consequences that it has to endure in the near future. The concept of awareness has to be generated at local level (Newport \& Jawahar, 2003), so that people can be prepared. In the context of disaster management, the role of the authorities is to implement disaster reduction programmes, but decision making should include the affected community. Without the awareness or involvement of local communities, such programmes often fail to yield results during disaster occurrences (Zhang, Yi, \& Zhao, 2013). The involvement of community could fill the gap in the planning and implementation of disaster reduction programmes. The result of community based disaster reduction programme can only be apparent when the affected population has a deep understanding of the disaster risk levels, hazard distribution characteristic, participate in the hazard elimination and risk mitigation activities. (Zhang et al., 2013).

A community prioritized actions for disaster risk reduction could lead to the adaptation process for reducing the impact of disaster (Prashar, Shaw, \& Takeuchi, 2013). The dissemination of disaster prevention knowledge can fortify public disaster prevention and reduction awareness (Zhang et al., 2013). According to Pearce (2003), the community members have the right to know and understand the hazard they should be expecting so they can plan for themselves and make informed choices thus reducing their vulnerability. The community involvement elates rural appraisal in the preparation of contingency plan that would fortify the community in response during disaster (Newport \& Jawahar, 2003). The preparation of community for disaster can include various things such as their knowledge on which route to take during disaster occurrences, the prioritized action during time of distress, the preparation before disaster hits and what to expect. With the expected knowledge safely engraved in the minds of affected community, the panic probability could be reduced and the community would able to act independently in the time of distress thus reducing the number of casualties. 
PLANNING MALAYSIA

Journal of the Malaysia Institute of Planners (2018)

\section{METHODOLOGY}

This research employs mainly quantitative approach and added with interviews with some of the respondents. The major interest of this research was to assess the awareness and preparedness of the affected communities for any untoward incidents in their area, especially related to dam failures. For the primary data collection, a questionnaire survey was conducted among the community members of the surrounding of the TNB Sultan Abu Bakar Hydroelectric Dam in Lembah Bertam, Cameron Highlands. The questionnaire was designed to elicit the perceptions of the community of the implementation of EWS in the area. EWS has been proposed by the dam authority as a primary caution system that would alert the community in hope that it can reduce the number of casualties in the event of dam failure. Meanwhile, literature review and document analysis were employed to obtain secondary information regarding Lembah Bertam and also regarding EWS as proposed by the dam authority.

\section{ANALYSIS AND FINDINGS}

In total 500 respondents answered the survey regarding their perceptions towards EWS implementation. The analysis was divided into two main sections; i) community experience with disaster; and ii) community perceptions towards the implementation of EWS.

\section{Community Experience with Disaster}

A correlation test was conducted in order to identify the significance between some of the demographic characteristics of the respondents and their disaster experience. The cross tabulation analysis shows the characteristics of respondents in relation to their experience. In order for a community to act independently during disaster, the considering factors are including demographic, gender and livelihood of the affected community.

Cross tabulation analysis between gender and disaster experience shows male respondents $(64.8 \%)$ have experienced disaster more than female respondents $(35.2 \%)$ (Table 1$)$.

Table 1: Disaster experience by gender

\begin{tabular}{lcccccc}
\hline \multicolumn{7}{c}{ Experienced disaster } \\
\hline Gender & No & $\%$ & Yes & $\%$ & Total & $\%$ \\
\hline Male & 147 & 57.4 & 158 & 64.8 & 305 & 61.0 \\
Female & 109 & 42.6 & 86 & 35.2 & 195 & 39.0 \\
\hline Total & 256 & 100.0 & 244 & 100.0 & 500 & 100.0 \\
\hline
\end{tabular}

In terms of age group, majority of the respondents that have disaster experience belong to the 20-30 years old age group (20.9\%) and the $31-40$ years 
Mohd Ramzi, Ismawi Zen, Rahsidi Sabri, Sivadass Thiruchelvam, Izawati Tukiman, \& Aishah Naqiah

Community Awareness on the Implementation of Early Warning System at Tenaga Nasional Berhad Sultan Abu Bakar

Hydroelectric Scheme, Lembah Bertam, Cameron Highland

age group $(20.5 \%)$ (Table 2). Whereas, the least number of the respondents that have disaster experience belongs in the $>60$ years old age group. However, the majority between all age groups that have no experience with disaster also belong to 20-30 years age group (25.8\%), followed by those in the $<20$ years age group $(21.9 \%)$. This data could be due to the majority of respondents that answer the survey belong to the 20-30 years age group.

Table 2: Disaster experience by age group

\begin{tabular}{lcccccc}
\hline \multicolumn{7}{c}{ Experienced disaster } \\
\hline Age & No & $\%$ & Yes & $\%$ & Total & Total \% \\
\hline$<$ 20 years & 56 & 21.9 & 40 & 16.4 & 96 & 19.2 \\
20-30 years & 66 & 25.8 & 51 & 20.9 & 117 & 23.4 \\
31-40 years & 53 & 20.7 & 50 & 20.5 & 103 & 20.6 \\
41-50 years & 23 & 9.0 & 38 & 15.6 & 61 & 12.2 \\
51-60 years & 40 & 15.6 & 45 & 18.4 & 85 & 17.0 \\
$>$ 60 years & 18 & 7.0 & 20 & 8.2 & 38 & 7.6 \\
\hline Total & 256 & 100.0 & 244 & 100.0 & 500 & 100.0 \\
\hline
\end{tabular}

In terms of ethnicity, the cross-tabulation result in Table 3 shows most of the Chinese have experienced disaster (34.0\%), while the majority of the Orang Asli Semai have not experienced disaster (60.9\%). This result could be due to the distribution of the population where the Chinese are mostly located in Lembah Bertam area, which is the most vulnerable area to flood risk compared to other areas surrounding the dam.

Table 3: Disaster experience by ethnicity

\begin{tabular}{lcccccc}
\hline \multicolumn{7}{c}{ Experienced disaster } \\
\hline Ethnicity & No & $\%$ & Yes & $\%$ & Total & Total \% \\
\hline Semai & 156 & 60.9 & 72 & 29.5 & 228 & 45.6 \\
Temiar & 6 & 2.3 & 0 & 0.0 & 6 & 1.2 \\
Malay & 21 & 8.2 & 39 & 16.0 & 60 & 12.0 \\
Chinese & 55 & 21.5 & 83 & 34.0 & 138 & 27.6 \\
Indian & 10 & 3.9 & 13 & 5.3 & 23 & 4.6 \\
Indonesian & 4 & 1.6 & 29 & 11.9 & 33 & 6.6 \\
Bangladesh & 2 & 0.8 & 8 & 3.3 & 10 & 2.0 \\
Others & 2 & 0.8 & 0 & 0.0 & 2 & 0.4 \\
\hline Total & 256 & 100 & 244 & 100.0 & 500 & 100.0 \\
\hline
\end{tabular}

\section{Community perceptions towards the implementation of EWS}

Table 4 shows the cross tabulation result between gender and respondents awareness of EWS. When comparing between gender, it is apparent that male respondents know more about EWS (62.5\%) compared to female (37.5\%). The significant Chi square value was $3.684, \mathrm{df}=1$ and $\mathrm{p}$-value $=.086$. These show 
PLANNING MALAYSIA

Journal of the Malaysia Institute of Planners (2018)

that male respondents were more aware of the disaster mitigation effort compared to females.

Table 4: EWS awareness by gender

\begin{tabular}{|c|c|c|c|c|c|c|c|}
\hline \multicolumn{8}{|c|}{ Know EWS x Gender } \\
\hline & Male & $\%$ & Female & $\%$ & Chi square & df & p-value \\
\hline $\begin{array}{l}\text { No } \\
\text { Yes }\end{array}$ & $\begin{array}{l}27 \\
278\end{array}$ & $\begin{array}{l}49.1 \\
62.5\end{array}$ & $\begin{array}{l}28 \\
167\end{array}$ & $\begin{array}{l}50.9 \\
37.5\end{array}$ & 3.684 & 1 & .086 \\
\hline
\end{tabular}

Table 5 shows the cross tabulation result between age and respondents awareness of EWS. The result indicates that majority of the respondents who were aware of EWS belong to the 20-30 years old age group (22.0\%). However, respondents from the same age group were also the majority without awareness of EWS (34.5\%). For age groups 41-50 years old and > 60 years old, most of them were aware of EWS and only a very small number of respondent in that specific age groups were not aware of EWS. They show a better awareness of EWS compared to other age groups. The Chi square value was $10.057, \mathrm{df}=5$ and $\mathrm{p}$-value $=.142$.

Table 5: EWS awareness by age group

\begin{tabular}{|c|c|c|c|c|c|c|c|}
\hline \multicolumn{8}{|c|}{ Know EWS x Age } \\
\hline & $\begin{array}{l}< \\
\text { years }\end{array}$ & 20 & $\begin{array}{l}20-30 \\
\text { years }\end{array}$ & $\begin{array}{l}31-40 \\
\text { years }\end{array}$ & $\begin{array}{l}41-50 \\
\text { years }\end{array}$ & $\begin{array}{l}51-60 \\
\text { years }\end{array}$ & $\begin{array}{ll}> & 60 \\
\text { years } & \end{array}$ \\
\hline No & 13 & & 19 & 11 & 1 & 7 & 4 \\
\hline$\%$ & 23.6 & & 34.5 & 20.0 & 1.8 & 12.7 & 7.3 \\
\hline Yes & 83 & & 98 & 92 & 60 & 78 & 34 \\
\hline$\%$ & 18.7 & & 22.0 & 20.7 & 13.5 & 17.5 & 7.6 \\
\hline
\end{tabular}

Chi square $=10.057, \mathrm{df}=5, \mathrm{p}$-value $=.142$

Table 6 shows the cross tabulation result between ethnicity and respondents awareness of EWS. The result reveals that majority of the respondents that know about EWS were the Semai people (45.6\%) and the least was other ethnicity $(0.2 \%)$. The Chi Square value was $13.228, \mathrm{df}=7$, p-value $=$ .163. This shows that although most of Semai people were located at Kg. Leryar, which is farthest from the dam area, they were mostly aware of EWS.

Table 6: EWS awareness by ethnicity

\begin{tabular}{|c|c|c|c|c|c|c|c|c|}
\hline \multicolumn{9}{|c|}{ Know EWS x Ethnicity } \\
\hline & Semai & Temiar & Malay & Chinese & Indian & Indonesia & Bangladesh & Others \\
\hline No & 25 & 1 & 6 & 13 & 3 & 2 & 4 & 1 \\
\hline$\%$ & 45.5 & 1.8 & 10.9 & 23.6 & 5.5 & 3.6 & 7.3 & 1.8 \\
\hline Yes & 203 & 5 & 54 & 125 & 20 & 31 & 6 & 1 \\
\hline$\%$ & 45.6 & 1.2 & 12.0 & 27.6 & 4.6 & 6.6 & 2.0 & 0.2 \\
\hline
\end{tabular}

Chi square $=13.228, \mathrm{df}=7, \mathrm{p}$-value $=.163$ 
Mohd Ramzi, Ismawi Zen, Rahsidi Sabri, Sivadass Thiruchelvam, Izawati Tukiman, \& Aishah Naqiah

Community Awareness on the Implementation of Early Warning System at Tenaga Nasional Berhad Sultan Abu Bakar

Hydroelectric Scheme, Lembah Bertam, Cameron Highland

\section{CONCLUSION}

Based on the results from the statistical analyses, it can be concluded that majority of the respondents were aware of the implementation of EWS. The findings have revealed that majority of the respondents with awareness, in terms of gender were male, and in terms of age were those in the 20-30 years old group. Although majority of the respondents were from Lembah Bertam, Semai people who were residing in Orang Asli villages were more aware of EWS. The results have also suggested that people with disaster experience are more attentive towards EWS compared to those without. The findings are in line with those of Karanci, Aksit and Dirik's (2005), and Osuret et al.'s (2016) who find that the influencing factors in the disaster related cognition behaviours are very much related to socio demographic, previous disaster experience, anxiety and locus of control.

\section{REFERENCES}

Karanci, A., Aksit, B., \& Dirik, G. (2005). Impact of a community disaster awareness training program in Turkey: Does it influence hazard-related cognitions and preparedness behaviors. Social Behavior and Personality: An International Journal, 33, 243-258.

Mercy Corps Nepal. (2010) Establishing community based early warning system.

Newport, J. K., \& Jawahar, G. G. P. (2003). Community participation and public awareness in disaster mitigation. Disaster Prevention and Management, 12(1), 33 36.

Osuret, J., Atuyambe, L. M., Mayega, R. W., Ssentongo, J., Tumuhamye, N.,... Bazeyo, W. (2016). Coping strategies for landslide and flood disasters: A qualitative study of Mt . Elgon Region, Uganda. PLOS Currents Disasters. doi: 10.1371/currents.dis. 4250a225860babf3601a18e33e172d8b.

Pearce, L. (2003). Disaster management and community planning, and public participation: How to achieve sustainable hazard mitigation. Natural Hazards, 28, 211-228.

Prashar, S., Shaw, R., \& Takeuchi, Y. (2013). Community action planning in East Delhi: A participatory approach to build urban disaster resilience. Mitigation and Adaptation Strategies for Global Change, 18(4), 429-448.

United Nations International Strategy for Disaster Reduction [UNISDR] (2009). UNISDR Terminology on Disaster Risk Reduction. 35. Retrieved from https://www.unisdr.org/files/7817_UNISDRTerminologyEnglish.pdf

Zhang, X., Yi, L., \& Zhao, D. (2013). Community-based disaster management: A review of progress in China. Natural Hazards, 65(3), 2215-2239 